Research Article

\title{
EFFECTS OF TURMERIC POWDER ON CLOSTRIDIUM PERFRINGENS LOAD IN BROILER CHICKENS
}

\author{
M.Z. Ali ${ }^{1 *}$, M.M. Islam ${ }^{2}$ and S. Zaman ${ }^{3}$ \\ ${ }^{1}$ Animal Health Research Division, Bangladesh Livestock Research Institute (BLRI) \\ Savar, Dhaka 1341, Bangladesh. \\ ${ }^{2}$ Nourish Poultry Diseases Diagnostic Laboratory, Nourish Poultry \& \\ Hatchery Ltd. Dhaka, Bangladesh. \\ ${ }^{3}$ Center for Advanced Research in Sciences, University of Dhaka, Dhaka 1000, Bangladesh.
}

\begin{abstract}
Necrotic enteritis (NE) is a major economic problem in broiler industry globally and is caused by Clostridium perfringens. The aim of the study was to know the effects of turmeric on $C$. perfringens in broiler chickens. A total of 3000-day-old Cobb 500 broiler chicks were divided into 6 groups and reared in environment control sheds with similar management. Each group contains 500 chicks and again divided into two subgroups as control and treatment with 250 chicks. In treatment groups added $2 \mathrm{gm} / \mathrm{kg}$ turmeric powder with basal feeds and reared up to 30 days and follow standard vaccine schedule. Intestinal samples were collected every week from each group to detect $C$. perfringens load. Bodyweight gain, feed conversion ratio (FCR) and mortality rates were also calculated. The findings were loads of $C$. perfringens in treatment groups decreased significantly compared to control groups. At $4^{\text {th }}$ week average count of $C$. perfringens was $4.44 \pm 0.12 \log C F U / g$ and $2.68 \pm 0.17$ $\log C F U / g$ in control and treatment groups, respectively. Average chick's mortality decreased significantly in treatment groups. The flock mortality was decreased significantly in treatment groups $(1.40 \%)$ compared to control groups $(2.17 \%)$. The FCR become significantly decreased in treatment groups (1.490) compared to control groups (1.571). Therefore, use of turmeric powder in broiler ration can reduce NE by decreasing $C$. perfringens loads and it could be a good source of non-antibiotic growth promoter in poultry towards reduce antibiotic resistance and consumer will get a pathogen free rich protein source.
\end{abstract}

Keywords: Clostridium perfringens, Necrotic enteritis, Broiler, Turmeric, Feed conversion ratio (FCR)

\footnotetext{
"Corresponding author: zulfekar@blri.gov.bd
} 


\section{INTRODUCTION}

Necrotic enteritis (NE) is a major concern for the broiler industry due to it has significant health and economic impact (Skinner et al., 2010). It can reduce 12.0\% body weight and not only that it increases $10.9 \%$ feed conversion ratio (FCR) (Wade and Keyburn, 2015). Thus, NE causes about USD878.19 to USD1480.52 financial loss per flock in the USA and USD 2 to 6 billion losses annually in the globe (Wade and Keyburn, 2015; Yang et al., 2019). Maximum digestion, absorption and metabolism of feeds are the key principal of broiler nutrition. NE hampered this physiology by necrosis of intestinal mucosa as well as nutrient absorption become decreased resulting in reduce FCR (Bhuiyan et al., 2019; Yang et al., 2019).

The major cause of NE is Clostridium perfringens, rod-shaped, spore-forming, gram-positive, anaerobic bacteria, and ubiquitously harbor in gut (Freedman et al., 2015; Miller et al., 2010). It could become pathogenic and causes NE in poultry when changing the dynamic balance of gut environment by starvation, stress, sudden change of feeds, and/or use of antibiotics as therapeutic purposes (Prescott, 2016; Ali, 2018). So, to prevent NE use of antibiotics as a growth promoter is the easy way of feed manufacturer (Silva et al., 2009). But bacteria become antibiotic resistance due to repeated use of antibiotics with feeds (Diarra et al., 2007; Nhung et al., 2017).

To save lives and microbial biodiversity an alternative use of antibiotics is the prime demand. Turmeric (Curcuma longa) is a natural herb under family- Zingiberaceae, extensively used as spice and coloring material in Asian countries. It can act as an important source for an alternative to antibiotics due to its antimicrobial properties. It is less toxic, residue-free and natural compared to synthetic antibiotics or inorganic chemicals (Khan et al., 2012). The active ingredients of turmeric are curcumin, tetrahydrocurcuminoids, demethoxycurcumin and bisdemethoxycutcumin and these are proven against bacteria (Niranjan and Prakash, 2008). Application of turmeric as a supplement in poultry feeds can play an important role in control NE by inhibiting $C$. perfringens and as well as feed efficiency becomes increased (Niranjan and Prakash, 2008; Khan et al., 2012). So, there is a need to explored and elucidate the safe alternatives of antibiotics to control NE. Therefore, the aim of the experimental study was to evaluate the effects of the turmeric powder on $C$. perfringens in intestines to control the NE and use of it instead of antibiotics.

\section{MATERIALS AND METHODS}

\section{Turmeric powder trial}

Experiment of turmeric powder trial as feed additives, a total 3000-day old Cobb500 unsexed broiler chicks were collected from Nourish Poultry and Hatchery Ltd. Dhaka, Bangladesh with history of same pedigree line. The chicks were divided randomly into 6 groups (replication) as G1, G2, G3, G4, G5, and G6 where 500 chicks present in each group and reared in 6 different sheds. Aga in chicks were 
divided into two subgroups within the group by metal wire net as treatment group $(n=250)$ and control group $(n=250)$. Birds were reared in artificial controlled house (Cumberland, USA) maintaining daylight, ventilation, air speed, humidity, temperature etc. In the treatment groups used $2 \mathrm{~g}$ turmeric powder per $\mathrm{kg}$ basal feed and in control groups fed only basal feed. Broiler pre starter (a mash feed) were fed during 0-11 days old age, broiler starter (a mash feed) were fed during 12-21 days age and broiler grower feed (pellet feed) were fed up to 30 days of age as basal feed. These are corn based ready feed manufactured by Nourish Poultry \& Hatchery Ltd. Dhaka, Bangladesh with $2950 \mathrm{kcal}, 3000 \mathrm{kcal}$ and $3050 \mathrm{kcal}$ energy in broiler pre starter, broiler starter and broiler grower feed, respectively. Artificial brooder was provided during first 10 days and standard management of feeder, waterer and floor space was provided uniform for all birds. Only rice husk used as bedding till $10^{\text {th }}$ days of age and then mixed dried saw dust $50 \%$ of total bedding materials. The vaccine schedule was eye drop at day 1 of age by Nobilis ${ }^{\circledR}$ Ma5 + Clone 30 (Intervet International B.V., The Netherlands), at $11^{\text {th }}$ and $18^{\text {th }}$ days of age Nobilis ${ }^{\circledR}$ Gumboro D78 (Intervet International B.V., The Netherlands) in drinking water, and finally used Nobilis ${ }^{\circledR}$ ND Clone 30 (Intervet International B.V., The Netherlands) at 22th day of age in drinking water, there was no use of any antibiotic during experimental period.

\section{Sample collection and processing for $C$. perfringens load analysis}

To assess the effects of turmeric powder on $C$. perfringens three healthy birds were selected randomly from each treatment and control group at 0 -day, $7^{\text {th }}$ day, $14^{\text {th }}$ day, $21^{\text {th }}$ day and $28^{\text {th }}$ day of age. Euthanized the birds with cervical dislocation by the help of veterinarian and ensure that all muscle contractions have ceased before beginning dissection. Used sterile scissors carefully made an incision through the skin and muscle from the mid abdomen to the breast to expose the abdominal cavity. Then the liver and spleen were separated from the gastrointestinal tract (GI tract). Cut the GI tract from the duodenal loop, just distal of gizzard and just proximal of cloacal vent. Removed the entire GI tract by gently freeing any remaining connective tissue still bound to the body cavity or any other organs and placed the GI tract in a sterile Whirl-Pac bag (Nasco, USA) for further processing. Then GI tract was placed onto a clean and sterile dissecting tray and cut into $10 \mathrm{~cm}$ sections from each duodenum, jejunum and ileum. The lumens of GI tract were spread and flush out the digesta by sterile PBS, and kept in sterile stomacher bags. Weight out the $25 \mathrm{~g}$ GI tract sections and stomached at $230 \mathrm{rpm}$ for $2 \mathrm{~min}$ by adding $250 \mathrm{ml}$ brain heart infusion (BHI) broth (Oxoid, UK) and then 6- fold decimal dilution was done. Then incubated for $24 \mathrm{~h}$ at $37^{\circ} \mathrm{C}$ in anaerobic vented jar with appropriate amount of anaerobic gas generating packs (Mitsubishi Gas Chemical America Inc., New York). 
Subsequentially, $100 \mu \mathrm{l}$ of pre-enriched BHI broth from each dilution was inoculated into plates of tryptose sulphite cycloserine (TSC) agar base (Oxoid, UK) enriched with 5\% egg yolk and supplemented with $\beta$ D-cycloserine (Oxoid, UK). The plates were sealed tightly, incubated for $24 \mathrm{~h}$ at $37^{\circ} \mathrm{C}$ upside down in anaerobic condition. The black colonies on plates were examined and counted for typical colonies of $C$. perfringens and results were recorded as log CFU/ml (Mwangi et al., 2019). Finally, the pure isolates were confirmed by the biochemical (lactose fermentation) and gram staining test.

\section{Body weight gain}

At the age of $30^{\text {th }}$ day, total live body weight and total feed consumption of all living birds from treatment and control pans of all 6 replicated were measured. According to the collected parameters the effects of turmeric powder on body weight gain and feed conversion ratio were calculated.

\section{Statistical analysis}

The data from sample collection and laboratory results were recorded as coding into Microsoft Excel spreadsheet 2010 (Microsoft Corporation, WA, USA). The $C$. perfringens colony count data were converted into $\log \mathrm{CFU} / \mathrm{ml}$ by $\log \mathrm{CFU} / \mathrm{mL}=$ Log10 (CFU / (dilution factor*aliquot)). Data regarding total feed intake and body weight gain were recorded daily and feed conversion ratio (FCR) was calculated on weekly basis. The FCR was calculated by dividing the feed intake by weight gain. Then the data of $\log \mathrm{CFU} / \mathrm{mL}$ and FCR on six treatment and control groups were subjected to one-way ANOVA (analysis of variance) by using GLM (General Linear Model). The mean comparison on treatment and control groups were calculated by using Duncan's multiple range tests. All statistical analysis was done in statistical package SPSS version 25 (2017) (IBM corp. New York, USA). The $P<0.05$ was used to determine the significance.

\section{RESULTS AND DISCUSSION}

The $C$. perfringens counts were decreased significantly $(p=0.003)$ in all six replications of turmeric trial compared to the control groups (Table 1). At day 1 of age in both control and treatment groups and at $1^{\text {st }}$ week of age in treatment groups $C$. perfringens counts was below detection limit $(<1.0 \log \mathrm{CFU} / \mathrm{g})$ in all six groups. On $2^{\text {nd }}$ week of age average count was $4.24 \pm 0.14 \mathrm{log} \mathrm{CFU} / \mathrm{g}$ in control groups whereas below detection limit $(<1.0 \log \mathrm{CFU} / \mathrm{g})$ in 4 treatment groups including G2, G4, G5, and G6. During culling at $4^{\text {th }}$ week of age average count declined significantly from $4.44 \pm 0.12 \log \mathrm{CFU} / \mathrm{g}$ to $2.68 \pm 0.17 \mathrm{log} \mathrm{CFU} / \mathrm{g}$ in control groups and treatment groups respectively. 
Table 1. The effects of turmeric powder on $C$. perfringens counts of broiler chicken.

\begin{tabular}{|c|c|c|c|c|c|c|c|c|c|c|c|c|}
\hline \multicolumn{11}{|c|}{ Count of $C$. perfringens $(\log \mathrm{CFU} / \mathrm{g})$} & \multirow{2}{*}{\multicolumn{2}{|c|}{-Mortality (\%) }} \\
\hline \multirow{2}{*}{ Group } & \multicolumn{2}{|c|}{ DOC } & \multicolumn{2}{|c|}{$1^{\text {st }}$ week } & \multicolumn{2}{|c|}{$2^{\text {nd }}$ week } & \multicolumn{2}{|c|}{$3^{\text {rd }}$ week } & \multicolumn{2}{|c|}{$4^{\text {th }}$ week } & & \\
\hline & $\mathrm{C}$ & $\mathrm{T}$ & $\mathrm{C}$ & $\mathrm{T}$ & $\mathrm{C}$ & $\mathrm{T}$ & $\mathrm{C}$ & $\mathrm{T}$ & $\mathrm{C}$ & $\mathrm{T}$ & $\mathrm{C}$ & $\mathrm{T}$ \\
\hline $\mathrm{G} 2$ & $<1.0$ & $<1.0$ & $3.85 \pm 0.00$ & $<1.0$ & $4.17 \pm 0.21$ & $<1.0$ & $4.25 \pm 0.38$ & $1.6 \pm 0.44$ & $4.50 \pm 0.08$ & $2.84 \pm 0.73$ & 1.80 & 1.20 \\
\hline G3 & $<1.0$ & $<1.0$ & $4.04 \pm 0.06$ & $<1.0$ & $4.30 \pm 0.70$ & $2.69 \pm 0.17$ & $4.17 \pm 0.13$ & $1.77 \pm 0.49$ & $4.60 \pm 0.71$ & $2.84 \pm 0.10$ & 2.00 & 1.60 \\
\hline G6 & $<1.0$ & $<1.0$ & $3.95 \pm 0.03$ & $<1.0$ & $4.00 \pm 0.13$ & $<1.0$ & $4.34 \pm 0.22$ & $1.60 \pm 0.42$ & $4.36 \pm 0.06$ & $2.47 \pm 0.47$ & 2.80 & 1.00 \\
\hline Average & $<1.0$ & $<1.0$ & $3.95 \pm 0.04$ & $<1.0$ & $4.24 \pm 0.14$ & $3.58 \pm 0.09$ & $4.32 \pm 0.14$ & $1.72^{\prime} \pm 0.12$ & $4.44 \pm 0.12$ & $2.68 \pm 0.17$ & 2.17 & 1.40 \\
\hline$p$ & $0.003 *$ & & & & & & & & & & 0.000 & \\
\hline
\end{tabular}

*Significant at the 0.05 level; $<1.0=$ not detected; $\mathrm{CFU}=$ colony forming unit; $\mathrm{DOC}=$ Day old chicks; $\mathrm{T}=$ Treatment $(2 \mathrm{gm}$ turmeric powder per kg basal feed); $\mathrm{C}=$ Control (only basal feed) 
The chicken mortality rates became significantly $(p=0.000)$ decreased in treatment group compared to the control groups. Average chicken mortality rates reported $2.17 \%$ in control groups and $1.40 \%$ in treatment groups (Table 1).

The effects of turmeric powder on FCR of broiler chicken have been demonstrated a significant $(p=0.002)$ association. The average FCR of control and treatment groups recorded 1.571 and 1.490 respectively (Table 2 ). About $17.33 \mathrm{~g}(2.22 \%)$ weight gain occurs in treatment groups compared to control groups.

Table 2. The effects of turmeric powder with basal feeds of broiler chickens on feed conversion ratio (FCR).

\begin{tabular}{|c|c|c|c|c|c|c|c|}
\hline \multirow{2}{*}{ Data } & \multicolumn{6}{|c|}{ Group } & \multirow{2}{*}{ Average } \\
\hline & G1 & G2 & G3 & G4 & G5 & G6 & \\
\hline Control & 1.533 & 1.504 & 1.685 & 1.583 & 1.56 & 1.563 & 1.571 \\
\hline Treatment & 1.501 & 1.458 & 1.537 & 1.566 & 1.444 & 1.43 & 1.49 \\
\hline Differences (g) & 16 & 28 & 21 & 9 & 11 & 19 & $17.33(2.22 \%)$ \\
\hline $\mathrm{p}$ & \multicolumn{7}{|c|}{0.002} \\
\hline
\end{tabular}

*Significant at the 0.05 level

Necrotic enteritis (NE) is a cause of $C$. perfringens that affects on feed utilization by disrupting the intestinal epithelium (Mwangi et al., 2019). The major clinical signs of NE have suddenly increased mortality, reduce weight gain, poor feed conversion, and necroses of intestinal mucosa are major postmortem lesions (Immerseel et al., 2004). The prevalence of $C$. perfringens type A is $64.73 \%$ in poultry and well known as a cause of foodborne illness and gas gangrene to humans (Khan et al., 2012; Songer, 1996). The prevalence of $\mathrm{NE}$ is demonstrated to be $8 \%$ in broiler chickens in Bangladesh (Miah et al., 2011).

Historically herbs and spices are being used as feed additives for farming animals due to its medicinal properties (Frankic et al., 2009). These natural plant products have been proven less toxic, with no residue, and antioxidant and antimicrobial effects so it is now being considered as the ideal feed supplement of livestock worldwide (Khan et al., 2012). Turmeric (Curcuma longa) is a natural herb and popular for medicinal properties. The active ingredients of turmeric are tetrahydrocurcuminoids, curcumin, demethoxycurcumin and turmerones that are proven with their anti-inflammatory, anti-carcinogenic, and antibacterial properties (Mitsch et al., 2004). Mitsch et al. (2004) shows the antibiotic property of turmeric on $C$. perfringens and concluded $2 \mathrm{gm} / \mathrm{kg}$ turmeric in feed supplements can inhibit the growth of $C$. perfringens. There is a rapidly growing interest to produce broiler meat without antibiotics and use of non-antibiotic growth promoters worldwide in order to maintain a bird's health and growth performance (Khan et al., 2012). 
The findings of research study included the use of turmeric powder in feed can reduce $C$. perfringens count significantly compared to control group. Researchers identified turmeric as having anti-inflammatory (Lee, 2016), wound healing, and anticancer (Kim et al., 2012) properties. Intestinal health was normal in treatment groups that help to increase absorption of dietary nutrients through smooth intestinal epithelium. As a result, FCR became significantly lower in treatment groups compared to control groups. These results are strongly supported by the experiment of Kafi et al. (2017) they demonstrated that use of turmeric in broiler feed at the rate of $0.75 \%$ level as feed additives can improve growth performance as well as increase profitability. Turmeric use in broiler ration can improve growth performance although its concentration, dose, and duration of use varies in different experiments like AL-Kassie et al. (2011) used as $0.75 \%$ to $1 \%$, AL-Sultan (2003) used as 0.5 to $1 \%$, and Ahmadi (2010) used as $0.9 \%$ in basal feed.

Antimicrobial resistance is an important health issue for both humans and animals globally including Bangladesh (Ahmed et al., 2019; Ali and Hasan, 2018). The use of antibiotics in animal and fish feeds as growth promoter though improve feed efficiency and increase growth but they are modifying intestinal flora and creating a selective pressure to develop antibiotic resistance which favor a resistant bacteria (Collier et al., 2003). So several European countries banned or restricted the use of antibiotic growth promoters in feed (Casewell et al., 2003). The Government of Bangladesh also completely banned antibiotics in animal and fish feeds as a growth promoter by Government of Bangladesh through Fish and Animal Feed Act-2010 (Fish and Animal Feed Act, 2010). The use of anticoccidial drugs and antibiotics in animal feeds to control coccidiosis and NE was the prime focus of animal feed manufacturers (M'Sadeq et al., 2015). Therefore, the application of turmeric in poultry feeds could be a good solution to prevent antimicrobial resistance. Finally, $2 \%$ turmeric powder supplements as feed additives in broiler ration could increase feed efficiency, production performance and decrease $C$. perfringens growth in intestine.

\section{CONCLUSIONS}

Turmeric (Curcuma longa) has been using as traditional herbal medicine and antimicrobial agents. It can be used as a natural growth promoter in broiler diet due to it can reduce $C$. perfringens load in gut, decrease necrotic enteritis as well as increase feed efficiency. However, further study on pharmacological activity, proper dose, and duration of use is required.

\section{ACKNOWLEDGEMENT}

The work was supported by grants of the Bangladesh Livestock Research Institute and Nourish Poultry \& Hatchery Ltd. 


\section{CONFLICTS OF INTEREST}

None of the authors have any conflict of interest to declare.

\section{REFERENCES}

Ahmadi, F. (2010). Effect of turmeric (Curcumin longa) powder on performance, oxidative stress state and some of blood parameters in broiler fed on diets containing aflatoxin B1. Global Veterinaria, 5(6): 312-317.

Ahmed, I., Rabbi, M.B. and Sultana, S. (2019). Antibiotic resistance in Bangladesh: A systematic review. International Journal of Infectious Diseases, 80: 54-61.

Ali, M.Z. and Hasan, M. (2018). Follow up of maternally derived antibodies titer against economically important viral diseases of chicken. Poultry Science Journal, 6(2):14954.

Ali, M.Z. (2018). The Seroprevalence Study of Reticuloendotheliosis Virus Infection in Chicken in Bangladesh. Egyptian Journal of Veterinary Science, 49(2): 179-86.

AL-Kassie, G.A., Mohseen, A.M. and Abd-AL-Jaleel, R.A. (2011). Modification of productive performance and physiological aspects of broilers on the addition of a mixture of cumin and turmeric to the diet. Research Opinions in Animal and Veterinary Sciences, 1: 31-34.

Al-Sultan, S.I. (2003). The effect of Curcuma longa (turmeric) on overall performance of broiler chickens. International Journal of Poultry Science, 2(5): 351-353.

Bhuiyan, Z.A., Ali, M.Z., Moula, M.M., Giasuddin, M. and Khan, Z.U.M. (2019). Prevalence and molecular characterization of infectious bronchitis virus isolated from chicken in Bangladesh. Veterinary World, 12(6): 909-915.

Casewell, M., Friis, C., Marco, E., McMullin, P. and Phillips, I. (2003). The European ban on growth-promoting antibiotics and emerging consequences for human and animal health. Antimicrobial Agents and Chemotherapy, 52(2): 159-161.

Collier, C.T., Van der Klis, J.D., Deplancke, B., Anderson, D.B. and Gaskins, H.R. (2003). Effects of tylosin on bacterial mucolysis, Clostridium perfringens colonization, and intestinal barrier function in a chick model of necrotic enteritis. Antimicrobial Agents and Chemotherapy, 47(10): 3311-3317.

Diarra, M.S., Silversides, F.G., Diarrassouba, F., Pritchard, J., Masson, L., Brousseau, R., Bonnet, C., Delaquis, P., Bach, S., Skura, B.J. and Topp, E. (2007). Impact of feed supplementation with antimicrobial agents on growth performance of broiler chickens, Clostridium perfringens and enterococcus counts, and antibiotic resistance phenotypes and distribution of antimicrobial resistance determinants in Escherichia coli isolates. Applied and Environmental Microbiology, 73(20): 6566-6576.

Fish and Animal Feed Act-2010. http://dls.portal.gov.bd/sites/default/files/files/dls.portal. gov.bd/page/b4ea0518_7cf7_43e5_b0b8_756b831991d4/1.\%20Fish\%20feed\%20and\% 20Animal\%20Feed\%20Act\%20-2010.pdf. Accessed 30 ${ }^{\text {th }}$ April 2020.

Frankic, T., Voljc, M., Salobir, J. and Rezar, V. (2009). Use of herbs and spices and their extracts in animal nutrition. Acta agriculturae Slovenica, 94(2): 95-102. 
Freedman, J.C., Theoret, J.R., Wisniewski, J.A., Uzal, F.A., Rood, J.I. and McClane, B.A. (2015). Clostridium perfringens type A-E toxin plasmids. Research in Microbiology, 166(4): 264-279.

IBM Corp. Released (2017). IBM SPSS Statistics for Windows, Version 25.0. Armonk, NY: IBM Corp. https://www.ibm.com/support/pages/how-cite-ibm-spss-statistics-or-earlierversions-spss. Accessed $30^{\text {th }}$ April 2020.

Immerseel, F.V., Buck, J.D., Pasmans, F., Huyghebaert, G., Haesebrouck, F. and Ducatelle, R. (2004). Clostridium perfringens in poultry: an emerging threat for animal and public health. Avian Pathology, 33(6): 537-549.

Kafi, A., Uddin, M.N., Uddin, M.J., Khan, M.M.H. and Haque, M.E. (2017). Effect of Dietary Supplementation of Turmeric (Curcuma longa), Ginger (Zingiber officinale) and their Combination as Feed Additives on Feed Intake, Growth Performance and Economics of Broiler. International Journal of Poultry Science, 16: 257-65.

Khan, R.U., Naz, S., Javdani, M., Nikousefat, Z., Selvaggi, M., Tufarelli, V. and Laudadio, V. (2012). The use of turmeric (Curcuma longa) in poultry feed. World's Poultry Science Journal, 68(1): 97-103.

Kim, J.H., Gupta, S.C., Park, B., Yadav, V.R. and Aggarwal, B.B. (2012). Turmeric

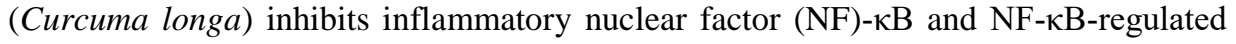
gene products and induces death receptors leading to suppressed proliferation, induced chemosensitization, and suppressed osteoclastogenesis. Molecular Nutrition and Food Research. 56(3): 454-65.

Lee, Y.J. (2016). Antimicrobial resistance and molecular characterization of Clostridium perfringens isolated from chicken. Journal of Preventive Veterinary Medicine, 40(2): 71-79.

Miah, M.S., Asaduzzaman, M., Sufian, M.A. and Hossain, M.M. (2011). Isolation of Clostridium perfringens, causal agents of necrotic enteritis in chickens. Journal of Bangladesh Agricultural University, 9(1): 97-102.

Miller, R.W., Skinner, J., Sulakvelidze, A., Mathis, G.F. and Hofacre, C.L. (2010). Bacteriophage therapy for control of necrotic enteritis of broiler chickens experimentally infected with Clostridium perfringens. Avian Diseases, 54(1): 33-40.

Mitsch, P., Zitterl-Eglseer, K., Kohler, B., Gabler, C., Losa, R. and Zimpernik, I. (2004). The effect of two different blends of essential oil components on the proliferation of Clostridium perfringens in the intestines of broiler chickens. Poultry Science, 83(4): 669-675.

M'Sadeq, S.A., Wu, S., Swick, R.A. and Choct, M. (2015). Towards the control of necrotic enteritis in broiler chickens with in-feed antibiotics phasing-out worldwide. Animal Nutrition, 1(1): 1-11.

Mwangi, S., Timmons, J., Fitz-Coy, S. and Parveen, S. (2019). Characterization of Clostridium perfringens recovered from broiler chicken affected by necrotic enteritis. Poultry Science, 98(1): 128-135.

Nhung, N.T., Chansiripornchai, N. and Carrique-Mas, J.J. (2017). Antimicrobial resistance in bacterial poultry pathogens: a review. Frontiers in Veterinary Science, 10(4): 126. 
Niranjan, A. and Prakash, D. (2008). Chemical constituents and biological activities of turmeric (Curcuma longa L.): a review. Journal of Food Science and Technology, 45(2): 109.

Prescott, J.F. (2016). Brief description of animal pathogenic Clostridia. In: Clostridial diseases of animals. Uzal, F.A., Songer, J.G., Prescott, J.F., editors. John Wiley and Sons, Ames, Iowa, Pp. 13-19.

Silva, R.O.S., Salvarani, F.M., Assis, R.A., Martins, N.R.S., Pires, P.S. and Lobato, F.C.F. (2009). Antimicrobial susceptibility of Clostridium perfringens strains isolated from broiler chickens. Brazilian Journal of Microbiology, 40(2): 262-264.

Skinner, J.T., Bauer, S., Young, V., Pauling, G. and Wilson, J. (2010). An economic analysis of the impact of subclinical (mild) necrotic enteritis in broiler chickens. Avian Diseases, 54(4): 1237-1240.

Songer, J.G. (1966). Clostridial enteric diseases of domestic animals. Clinical Microbiology Reviews, 9(2): 216.

Wade, B. and Keyburn, A. (2015). The cost of necrotic enteritis is huge. World Poultry News 2015; 31:5.

Yang, W.Y., Lee, Y.J., Lu, H.Y., Branton, S.L., Chou, C.H. and Wang, C. (2019). The net Bpositive Clostridium perfringens in the experimental induction of necrotic enteritis with or without predisposing factors. Poultry Science, 98(11): 5297-5306. 